\title{
TRICHOSPORON SPECIES ISOLATED FROM THE PERIGENITAL REGION, URINE AND CATHETERS OF A BRAZILIAN POPULATION
}

\author{
Agenor Messias Silvestre Junior ${ }^{1}$, Mauricio Alexandre Bandeira Rampazzo Miranda ${ }^{2}$, Zoilo Pires de Camargo ${ }^{1}$ \\ ${ }^{1}$ Universidade Federal de São Paulo, Disciplina de Biologia Celular, São Paulo, SP, Brasil; ${ }^{2}$ Total Laboratórios, São Paulo, Brasil.
}

Submitted: August 24, 2009; Approved: March 29, 2010.

\begin{abstract}
The present study aimed to 1) determine the colonization rates of medically important Trichosporon species on normal perigenital skin and 2) determine the isolation rates of Trichosporon spp. isolated from the urine and catheters of Brazilian patients hospitalized in the Intensive Care Unit (ICU). The overall colonization rate of Trichosporon spp. was $11.15 \%$ (112 isolates). The most common species isolated from normal perigenital skin was T. cutaneum (29.46\%), followed by T. asteroides (20.53\%), T. ovoides (15.17\%), T. inkin (10.71\%), T. mucoides (8.92\%), and T. asahii (6.25\%). From urine and catheters, T. asahii was the species most commonly isolated $(76.5 \% ; \mathrm{n}=23)$, followed by $T$. inkin $(16.6 \% ; \mathrm{n}=5)$ and $T$. asteroides $(6.6 \% ; \mathrm{n}=2)$. In addition, the highest isolation rate occurred in subjects in the 71 - to 80 -yearold age range $(36.7 \% ; n=11)$, followed by 61 to $70(26.7 \% ; n=8), 51$ to $60(13.3 \% ; n=4), 31$ to 40 $(13.33 \% ; n=4)$, and 41 to $50(10 \% ; n=3)$. We concluded that 6 medically important species of the genus Trichosporon colonize the perigenital region in a normal population. The identification of these species is possible by means of classical methods but often requires repeated analyses repetitions due to difficulties in the assimilation process. In contrast, only 3 species of Trichosporon were isolated from urine and catheters.
\end{abstract}

Key words: Trichosporon spp., epidemiology, perigenital skin, superficial mycosis.

\section{INTRODUCTION}

Trichosporon is a genus of anamorphic basidiomycetous yeast widely distributed in nature and which can form part of the human mycobiota (17). This fungus belongs to a medically important genus that includes the causative agents of deepseated, mucosa-associated and superficial infections (13, 21, 34). These arthroconidial yeasts are well known as agents of white piedra $(11,13,21,34)$, but they are also reported to be opportunistic pathogens causing deep-seated and widely disseminated infections in immunocompromised patients $(4,9$, 34).

Diagnosis of trichosporonosis is difficult and is often not confirmed until autopsy. A definitive diagnosis of disseminated trichosporonosis is usually established by histological examination of tissue samples obtained by biopsy as well as by detecting the causative pathogenic fungi in clinical samples (20).

\footnotetext{
*Corresponding Author. Mailing address: Universidade Federal de São Paulo - UNIFESP, Disciplina de Biologia Celular, 04023-062 Rua Botucatu,
} 862/8ªndar, São Paulo, SP, Brasil.; Tel.: 5511 5576-45 23.; E-mail: zpcamargo@unifesp.br 
Identification of species from the Trichosporon genus by conventional methods is often difficult and is frequently inconclusive. This situation is further complicated by the lack of in vitro standardized sensitivity tests. These obstacles have resulted in the limited availability of information on the epidemiology, diagnosis and therapeutics of trichosporonosis $(4,11,27)$. Gueho et al. (11) revised the taxonomy of the genus Trichosporon, whereas Sugita et al. (29, 30) proposed to classify the genus Trichosporon into 17 species. Seven morphological and biochemical patterns were recognized among clinical isolates associated with human infections: $T$. asahii, T. asteroides, T. cutaneum, T. inkin, T. jirovecii, T. mucoides and T. ovoides. Rodrigues-Tudela et al. (27) proposed a correct identification of the Trichosporon species by molecularly sequencing the intergenic spacer 1 (IGS1) of the rRNA gene. T. asahii appears to be more frequent in cases of systemic infection by Trichosporon species than in superficial infections $(1,2)$. In 2002, Sugita et al. (31) proposed classifying 25 species in the genus Trichosporon and suggested that 8 of these should be considered relevant as potential human pathogens, including two emergent species, $T$. domesticum and T. montevideense. Shortly thereafter, the same group published a study wherein they identified 36 Trichosporon species (32), including five new species proposed by Middelhoven et al. (18), T. vadense, T. smithiae, T. dehoogii, T. scarabaeorum and T. gamsii.

Traditionally, Trichosporon spp. are characterized by the presence of hyphae, pseudohyphae, blastoconida and arthroconidia, with morphological features that vary based on species and on their biochemical properties of carbon assimilation $(1,5,10,11,13,33,34)$. There is a general consensus that molecular methods are required for accurate identification of this genus, but these methods are costly and not practical for most routine laboratories $(26,31)$. Despite the difficulties in identifying Trichosporon species by classical methodologies (morphological and biochemical characteristics), here, we use traditional techniques to analyze the epidemiological aspects of medically important Trichosporon spp. in a local Brazilian population.

\section{MATERIAL AND METHODS}

\section{Patient selection and origins of Trichosporon isolates}

From March 2006 to March 2008, 1004 normal male asymptomatic subjects were examined for superficial lesions in the Dermatology Department of São Paulo Hospital - Federal University of São Paulo (UNIFESP) and Heliópolis Hospital. The protocol was approved by the University Human Ethics Committee, and signed consent was obtained from each subject. These educationally diverse subjects, whose ages ranged from 03 to 70 years, included Caucasians, Blacks, Asians and others of mixed race. The square carpet technique used for the isolation of Trichosporon spp. was done based on the reports of Mariat and Tapia (14) and Mariat and AdanCampos (15). At the moment of consultation, the subjects received a square of sterilized wool carpet to rub on their perigenital skin regions (scrotal, inguinal and perianal regions). The squares were then inoculated onto Sabouraud dextrose agar plates (Difco) supplemented with chloramphenicol (500 $\mu \mathrm{g} / \mathrm{ml})$. Culture plates were incubated at room temperature (25$28^{\circ} \mathrm{C}$ ) and observed daily for growth for up to 4 weeks. All cultures suspected of being of positive for Trichosporon genus were suebcultured onto Sabouraud dextrose agar tubes. Gross morphology and microscopic characteristics were analyzed. Slide cultures of each isolate were also prepared for observation by optical microscopy (25).

During the same time period, 26 Trichosporon spp. isolated from urine and 4 Trichosporon spp. isolated from the catheters of 30 male patients hospitalized in the Intensive Care Unit (ICU), due to various health problems, were also studied. These patients were 30 to 80 years old and had presented serious physical and health conditions, but none had received a diagnosis of trichosporonosis. All patients were Caucasian with elementary school educational levels.

\section{Biochemical and morphological identification of suspected Trichosporon isolates}

All suspicious primary isolates were subcultured onto Sabouraud dextrose agar without antibiotics for 10 days at 
room temperature. The cultures were first screened by colonial and microscopic morphology and then by analyzing their physiological characteristics of growth on carbon and nitrogen sources (assimilation patterns), growth at various temperatures, ability to hydrolyze urea, growth in $0.1 \%$ cycloheximide, and presence of appressorial cells (5).

\section{RESULTS}

Trichosporon species, which were identified by morphological and biochemical tests, were recovered from 112 $(11.15 \%)$ out of the 1004 normal asymptomatic subjects examined. However, only $102(91.1 \%)$ of isolates could be identified at the species level. Ten isolates (8.92\%) were inconclusive to assimilation pattern tests.

The following species were identified: T. cutaneum (29.46\%), T. asteroids (20.53\%), T. ovoides (15.17\%), T. inkin (10.71\%), T. mucoides (8.92\%), and T. asahii (6.25\%). With respect to the identification of Trichosporon species by classical methodology, for some isolates it was necessary to repeat the assimilation test 2 to 3 times due to inconclusive initial results. In those cases, when a more intense inoculum was cultured onto the medium, a halo of assimilation could be better visualized.

The colonization rates of genus Trichosporon varied greatly by age and, to a lesser extent, by the race or educational level of the patient. Figures $1 \mathrm{~A}$ and $1 \mathrm{~B}$ show the percentages of isolates according to race and educational level.

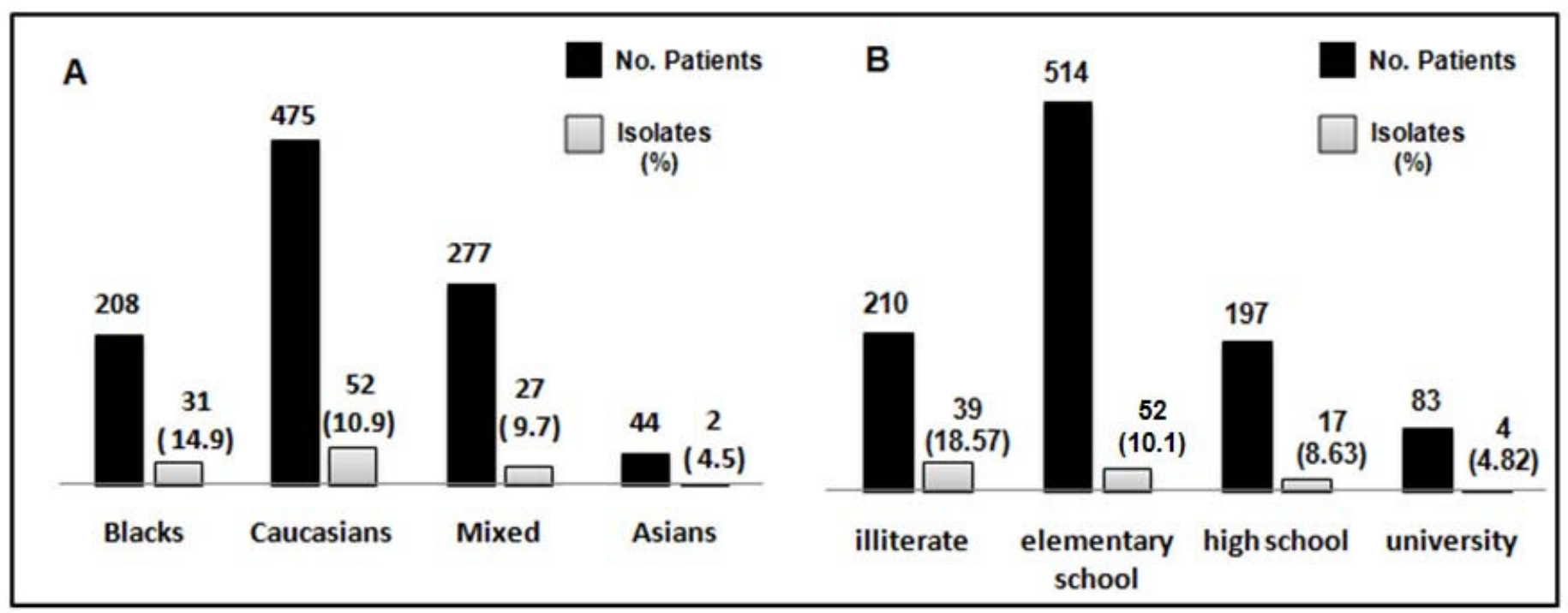

Figure 1. Number of individuals and colonization rates of Trichosporon spp. on perigenital skin according to race (A) and educational level (B). The percentage is relative to each group.

Table 1 shows the different Trichosporon species isolated from the perigenital skin area according to age. Skin colonization was higher among subjects aged 21 to $30(48.2 \%)$ and 31 to $40(25.0 \%)$ years, and all six relevant species of medical interest were present. Among the 112 Trichosporon spp. isolates, T. cutaneum was the most frequently isolated species (29.46\%), followed by $T$. asteroides (20.53\%), T. ovoides (15.17\%), T. inkin (10.71\%), T. mucoides $(8.92 \%)$, and T. asahii $(6.25 \%)$. Ten isolates $(8.92 \%)$ could not be identified by phenotypic tests. Trichosporon isolates from the illiterate subject group comprised $18.57 \%$, followed by subjects in elementary school (10.12\%), high school (8.63\%), and university graduates $(4.82 \%)$.

Among the group of patients hospitalized in the ICU, 30 
Trichosporon spp., 26 from urine and 4 from catheters, were identified. Each isolate was obtained from a different patient. T. asahii was the most isolated species $(\mathrm{n}=23 ; 76.66 \%)$, followed by $T$. inkin $(\mathrm{n}=5 ; 16.66 \%)$ and $T$. asteroides $(\mathrm{n}=2$; $6.6 \%$ ) (Table 2). Based on age ranges, the 71- to 80-year-old group represented $36.7 \%$ of the isolates, followed by subjected aged 61 to $70(26.7 \%), 51$ to $60(13.33 \%), 31$ to $40(13.33 \%)$ and 41 to $50(10 \%)$. All of these subjects had attended elementary school.

Table 1. Colonization rates of Trichosporon species isolated from the perigenital skin of male asymptomatic volunteers according to age.

\begin{tabular}{|c|c|c|c|c|c|c|c|}
\hline SPECIES & \multicolumn{6}{|c|}{ AGES } & TOTAL \\
\hline & $\begin{array}{r}0-10 \\
(n=59) \\
\end{array}$ & $\begin{array}{c}11-20 \\
(n=166)\end{array}$ & $\begin{array}{r}21-30 \\
(n=357) \\
\end{array}$ & $\begin{array}{r}31-40 \\
(n=222) \\
\end{array}$ & $\begin{array}{r}41-50 \\
(n=134) \\
\end{array}$ & $\begin{array}{c}51-70 \\
(n=66)\end{array}$ & $\mathrm{N}(\%)$ \\
\hline T. asahii & & 4 & 1 & 1 & & 1 & $7(6.25)$ \\
\hline T. asteroides & & 4 & 11 & 6 & 1 & 1 & $23(20.53)$ \\
\hline T. ovoides & & 2 & 8 & 3 & 2 & 2 & $17(15.17)$ \\
\hline T. mucoides & & 4 & 1 & 2 & 3 & & $10(8.92)$ \\
\hline T. inkin & 2 & & 7 & 1 & 1 & 1 & $12(10.71)$ \\
\hline T. cutaneum & 1 & & 20 & 11 & & 1 & $33(29.46)$ \\
\hline Trichosporon spp. & & & 6 & 4 & & & $10(8.92)$ \\
\hline TOTAL & $\begin{array}{c}3 \\
(2.67 \%)\end{array}$ & $\begin{array}{c}14 \\
(12.5 \%)\end{array}$ & $\begin{array}{c}54 \\
(48.2 \%)\end{array}$ & $\begin{array}{c}28 \\
(25 \%)\end{array}$ & $\begin{array}{c}7 \\
(6.25 \%)\end{array}$ & $\begin{array}{c}6 \\
(5.35 \%)\end{array}$ & $112(100)$ \\
\hline
\end{tabular}

Table 2. Isolation rates of Trichosporon species isolated from urine and catheters according to age.

\begin{tabular}{|c|c|c|c|c|c|c|}
\hline \multirow[t]{2}{*}{ SPECIES } & \multicolumn{6}{|c|}{ AGE (years) } \\
\hline & $31-40$ & $41-50$ & $51-60$ & $61-70$ & $71-80$ & TOTAL \\
\hline T. asahii & 4 & 3 & $4 *(2)$ & 4 & 8 & $23(76.66 \%)$ \\
\hline T. inkin & - & - & - & $3^{*(1)}$ & $2^{*(1)}$ & $5(16.66 \%)$ \\
\hline T. asteroides & - & - & - & 1 & 1 & $2(6.66 \%)$ \\
\hline TOTAL & $4(13.33 \%)$ & $3(10 \%)$ & $4(13.33 \%)$ & $8(26.7 \%)$ & $11(36.7 \%)$ & $30(100 \%)$ \\
\hline
\end{tabular}

$*(\mathrm{n})=$ isolated from catheter $(2 T$. asahii and $2 T$. inkin $)$

\section{DISCUSSION}

This study identifies both biochemical and morphological aspects of the largest number of Trichosporon samples by species level (121 from superficial sites and 30 deep seated).
Although Trichosporon species include a heterogeneous group of arthroconidia-forming yeasts, this characteristic by itself has very low distinctive value in the identification of different species, since other yeasts are also able to form these structures $(4,12)$. Conventional carbon and nitrogen 
assimilation tests (auxonograms) are easy to perform but frequently need to be repeated several times until the results are confirmed. If classical tests are not sufficient to identify Trichosporon species, molecular approaches must be used (20, 23, and 27).

This is the first time since the creation of the new classification scheme of the genus Trichosporon $(27,28,32)$ that 6 of the 7 medically important species have been isolated and identified from the normal perigenital region. Although the natural habitat of Trichosporon is considered to be the soil, little is known about its colonization in normal skin (6). In our previous study in 1980 on genital white piedra among 300 young students, we isolated $33 \%$ of Trichosporon yeasts from normal perigenital skin and $25 \%$ from scrotal hairs using the carpet square technique. On that occasion, the fungus isolated was identified as T. beigelii (7). In Brazil, T. inkin and T. asahii have also been reported to colonize the hair shaft in the anal and perianal regions of HIV-positive patients (22). T. cutaneum was recently identified in an outbreak of scalp white piedra in a Brazilian child daycare center (28).

In the present study, we found that the genus Trichosporon colonizes the perigenital region of the normal population at a rate of $11.15 \%$. In addition, we found that the most isolated species included 6 of the 7 medically important Trichosporon species. T. cutaneum (29.46\%) and T. asteroides (20.53\%) were the most isolated species, followed by $T$. ovoides (15.17\%), T. inkin (10.71\%), T. mucoides (8.92\%), and T. asahii (6.25\%). Young adult subjects aged 21 to 30 years presented the highest colonization rate (54 isolates, $48.21 \%$ ), followed by the groups aged 31 to 40 (28 isolates; $25.0 \%$ ), 11 to 20 (14 isolates; $12.5 \%$ ), 51 to 70 (6 isolates; $5.35 \%$ ), 41 to 50 (7 isolates; $6.25 \%$ ), and 0 to 10 (3 isolates; $2.67 \%$ ) years. All 6 species were isolated from the groups aged 21 to 30 and 31 to 40 years, indicating that, in young adult males, the colonization rates of Trichosporon spp. are higher and that almost all species of medical interest are present. The role of these species as microbiota in the perigenital region is unknown but constitutes a focus for possible contamination of catheters and urethrae.
Based on our results, we conclude that 6 out of the 7 medically important Trichosporon spp. species are part of the normal perigenital skin mycobiota in males of all ages. Although we cannot determine whether this site is the main source of infection by the use of catheters, it is a possible source of urinary tract infection due to contact of the penis (urethra) with this region.

Our study also showed that $T$. asahii was the species most frequently isolated from urine and catheters (76.6\%), which is in contrast to what was found for the perigenital skin region $(6.25 \%)$. The ICU patients studied herein presented several important factors that may contribute to the disruption of the skin-mucosa barrier; however, none of them had been diagnosed with trichosporonosis. Girmenia et al. (8) reported that the most common underlying conditions related to trichosporonosis were hematological diseases, peritoneal dialysis and solid tumors. These risk factors are often found in ICU patients. Moretti-Branchini et al. (19) reported two Brazilian cases of Trichosporon-invasive infections in patients undergoing bone marrow transplantation. One of these patients had an intravascular catheter tip culture test return positive for T. inkin; the second patient was neutropenic, and the culture was identified as T. asahii. Ribeiro et al. (24) performed sequencing analysis of the IGS1 region of Trichosporon spp. isolated from Brazilian patients. This analysis revealed that different Trichosporon spp. could be grouped into distinct clades and that, in superficial regions, T. asahii was the predominant species (43\%), followed by $T$. faecale (24\%) and T. inkin (14\%). Furthermore, T. asahii (83\%) and T. inkin $(17 \%)$ were isolated from deep sites. Chagas-Neto et al. (3) analyzed bloodstream infections due to Trichosporon spp. by sequencing IGS1 and found that $T$. asahii was the prevailing species, followed by $T$. asteroides, $T$. coremiiforme and $T$. dermatis.

Invasive infections caused by Trichosporon spp. are commonly associated with the use of central venous catheters (CVC. In the present study, we identified four isolates from CVC, with T. inkin and T. asahii being identified twice in each. In urinary infections, $T$. asahii was the most isolated species. 
Our data agree with previous reports demonstrating that $T$. asahii is the most frequently isolated species from patients presenting risk factors $(2,13,16,33-35)$.

In conclusion, this study has demonstrated that 6 out of 7 the medically important Trichosporon species are present in the perigenital region of normal male subjects and that the type of species present correlates with age. In urine and catheters of ICU patients, 3 Trichosporon species were isolated, but $T$. asahii was the most frequently isolated species.

\section{ACKNOWLEDGEMENTS}

The authors thank FAPESP, CNPq and CAPES for fundings. We thank Dr. Jacob Levites from Heliópolis Hospital and Dr. Jane Tomimori-Yamashita (São Paulo Hospital).

\section{REFERENCES}

1. Barnett, J.A.; Payne, R.W.; Yarrow, D. (2000). Yeasts: characteristics and identification. 3rd ed. Cambridge University Press, Cambridge, United Kingdom.

2. Biasoli, M.S.; Carlson, D.; Chiganer, G.J.; Parodi, R.; Greca, A.; Tosello, M.E.; Luque, A.G.; Montero, A. (2008). Systemic infection caused by Trichosporon asahii in a patient with liver transplant. Med. Mycol. 46, 719-723.

3. Chagas-Neto, T.C.; Chaves, G.M.; Colombo, A.L. (2008). Update on the genus Trichosporon. Mycopathol. 3, 121-132.

4. Chagas-Neto, T.C.; Chaves G.M.; Melo, A.S.A.; Colombo, A.L. (2009). Bloodstream infections due to Trichosporon spp.: Species distribution, Trichosporon asahii genotypes determined on the basis of ribosomal DNA intergenic spacer 1 sequencing, and antifungal susceptibility testing. J. Clin. Microbiol., 47, 1074-1081.

5. De Hoog, G.S.; Guarro, J.; Gene, J.; Figueras, M.J. (2000). Atlas of clinical fungi. The Netherlands, Centraalbureau voor Schimmelcultures, Universitat Rovira i Virgili, Utrecht/Réus.

6. Ellner, K.; McBride, M.E.; Rosen, T.; Berman, D. (1991). Prevalence of Trichosporon beigelii. Colonization of normal perigenital skin. J. Med. Vet. Mycol., 29, 99- 103.

7. Fischman, O.; Camargo, Z.P.; Meireles, M.C.A. (1980). Genital white piedra: an emerging new fungal disease? Fifth International conference on the mycoses. Superficial, cutaneous, and subcutaneous infections. Caracas, Venezuela. Scientific publication no. 396. p.70-76.

8. Girmenia, C.; Pagano, L.; Martino, B.; D'antonio, D.; Fanci, R.; Specchia, G. (2005). Invasive Infections Caused by Trichosporon Species and Geotrichum capitatum in Patients with Hematological
Malignancies: a Retrospective Multicenter Study from Italy and Review of the Literature, J. Clin. Microbiol., 43, 1818-1828.

9. Gross, J.W.; Kan, V.L. (2008). Trichosporon asahii infection in an advanced AIDS patient and literature review. AIDS. 22, 793-795.

10. Gueho, E.; Faergemann, J.; Lyman, C.; Anassie, E.J. (1994). Malassezia and Trichosporon: two emerging pathogenic basidiomycetous yeast-like fungi. J. Med. Vet. Mycol. 32 (Suppl. 1): 367-378.

11. Gueho, E.; Smith, M.T.; de Hoog, G.S.; Billon-Grand, G.; Christen, R.; Batenburg-van der Vegte, W.H. (1992). Contributions to a revision of the genus Trichosporon. Antonie Van Leeuwenhoek. 61, 289-316.

12. Hou-Min, L.; Hong-Tao, D.; Wei, L.; Zei , W.; Ruo-Yu, L. (2005). Microbiological characteristics of medically important Trichosporon species. Mycopathol. 160, 217-225.

13. Hoy, J.; Hsu, K.C. ; Rolston, K. ; Hopfer, R.L. ; Luna, M. ; Bodey, G.P. (1986) Trichosporon beigelii infection: a review. Rev. Infect. Dis. 8, 959967.

14. Mariat, F. ; Adan-Campos, C. (1967). La téchnique du carré de tapis, méthode simple de prélèvement dans les mycoses superficielles. Ann. Inst .Pasteur (Paris). 113, 666-668.

15. Mariat, F.; Tapia, G. (1966). Dénombrement des champignons kératinophiles d'une population de Cynocéphales (Papio papio). Ann. Parasitol. (Paris). 41, 627-234.

16. Meyer, M.H.; Letscher, V.; Walter, J.; Lutz, P.; Marcellin, L.; Herbrecht, R. (2002) Chronic dissem inated Trichosporon asahii infection in a leukemic child. Clin. Infect. Dis. 35, 22-25.

17. Middelhoven, W.J.; Scorzetti, G.; Fell, J.W. (1999). Trichosporon guehoae sp nov., an anamorphic basidiomycetous yeast. Can J Microbiol. 45, 686-690.

18. Middelhoven, W.J; Scorzetti, G.; Fell, J.W. (2004). Systematics of the anamorphic basidiomycetous yeast genus Trichosporon Behrend with the description of five novel species: Trichosporon vadense, T. smithiae, T. dehoogii, T. scarabaeorum and T. gamsii. Int. J. Syst. Evol. Microbiol. 54, 975-986

19. Moretti-Branchini, M. L.; Fukushima, K.; Schreiber, A.Z.; Nishimura, K.; Papaiordanou, P. M.; Trabasso, P.; Tanaka, R.; Miyaji, M. (2001). Trichosporon species infection in bone marrow transplanted patients. Diag. Microbiol. Infec. Dis. 39, 161-164.

20. Nagai, H.; Yamakami, Y.; Hashimoto, A.; Tokimatsu, I.; Nasu, M.(1999). PCR detection of DNA specific for Trichosporon species in serum of patients with disseminated trichonosporosis. J. Clin. Microbiol. 37, 694-699.

21. Nahass, G.T.; Roseberg, S.P.; Leonardi, C.L.; Penneys, N.S. (1993). Disseminated infection with Trichospororn beigelii. Arch. Dermatol. 129, 1020-1023.

22. Pontes, Z.B.V.S.; Lima, E.O.; Ramos, A.L.; Frade, J.D.M.S.; Oliveira, N.M.C. (2002). Espécies de Trichosporon Behrend: colonização anal e piedra branca gênito-púbica em pacientes HIV+. Rev. Bras. Anal. Clin. 34, 173-175.

23. Pryce, T.M.; Palladino, S.; Kay, I.D.; Coombs, G.W. (2003). Rapid 
24. identification of fungi by sequencing the ITS1 and ITS2 regions using an automated capillary electrophoresis system. Med. Mycol. 41, 369-381.

25. Ribeiro, M.A.; Alastruey-Isquierdo, A.; Gomez-Lopes, A.; RodriguezTudela, J.L.; Cuenca-Estrella, M. (2008). Molecular identification and susceptibility testing of Trichosporon isolates from a Brazilian hospital. Rev. Iberoam. Micol. 25, 221-225.

26. Riddell, R.W. (1950). Permanent stained mycological preparation obbtained by slide culture. Mycologia. 42, 265-270.

27. Rodriguez-Tudela, J. L.; Diaz-Guerra, T. M.; Mellado, E.; Cano, V.; Tapia, C.; Perkins, A.; Gomez-Lopez, A.; Rodero, L.; Cuenca-Estrella, M.(2005). Susceptibility patterns and molecular identification of Trichosporon species. Antimicrob. Agents Chemother. 49, 4026-4034.

28. Roselino, A.M.; Seixas, A.B.; Thomazini, J.A.; Maffei, C.M.L. (2008). An outbreak of scalp white piedra in a Brazilian children day care. Rev. Inst. Med. Trop. S. Paulo. 50, 307-309.

29. Sugita, T.; Nishikawa, A.; Shinoda, T.; Kume, H. (1995). Taxonomic position of deep-seated, mucosa-associated, and superficial isolates of Trichosporon cutaneum from trichosporonosis patients. J. Clin.
Microbiol. 33, 1368-70.

30. Sugita, T.; Nishikawa, A. ; Shinoda, T. (1998). Identification of Trichosporon asahii by PCR based on sequences of the internal transcribed spacer regions. J. Clin. Microbiol. 36, 2742-2744.

31. Sugita, T.; Nakajima, M,; Ikeda, R.; Matsushima, T.; Shinoda, T. (2002). Sequence analysis of the ribosomal DNAintergenic spacer 1 regions of Trichosporon species. J. Clin. Microbiol. 40, 1826-30.

32. Sugita, T.; Ikeda, R.; Nishikawa, A. (2004). Analysis of Trichosporon isolates obtained from the houses of patients with summertype hypersensitivity pneumonitis. J. Clin. Microbiol. 42, 5467-5471.

33. Walsh, T.J.; Newman, K.R.; Moody, M.; Wharton, R.C.; Wade, J.C. (1989) Trichosporonosis in patients with neoplasic disease. Medicine (Baltimore). 65, 268-279.

34. Walsh, T.J. (1989). Trichosporonosis. Infec. Dis. Clin. N. Am., 3, 43-52. Wolf, D.G.; Falk, R.; Hacham, M.; Theelen, B.; Boekhout, T.; Scorzetti, G.; Shapiro, M.; Block, C.; Salkin, I.; Polacheck, I. (2001). Multidrugresistant Trichosporon asahii infection of nongranulocytopenic patients in three intensive care units. J. Clin. Microbiol., 39, 4420-4425. 